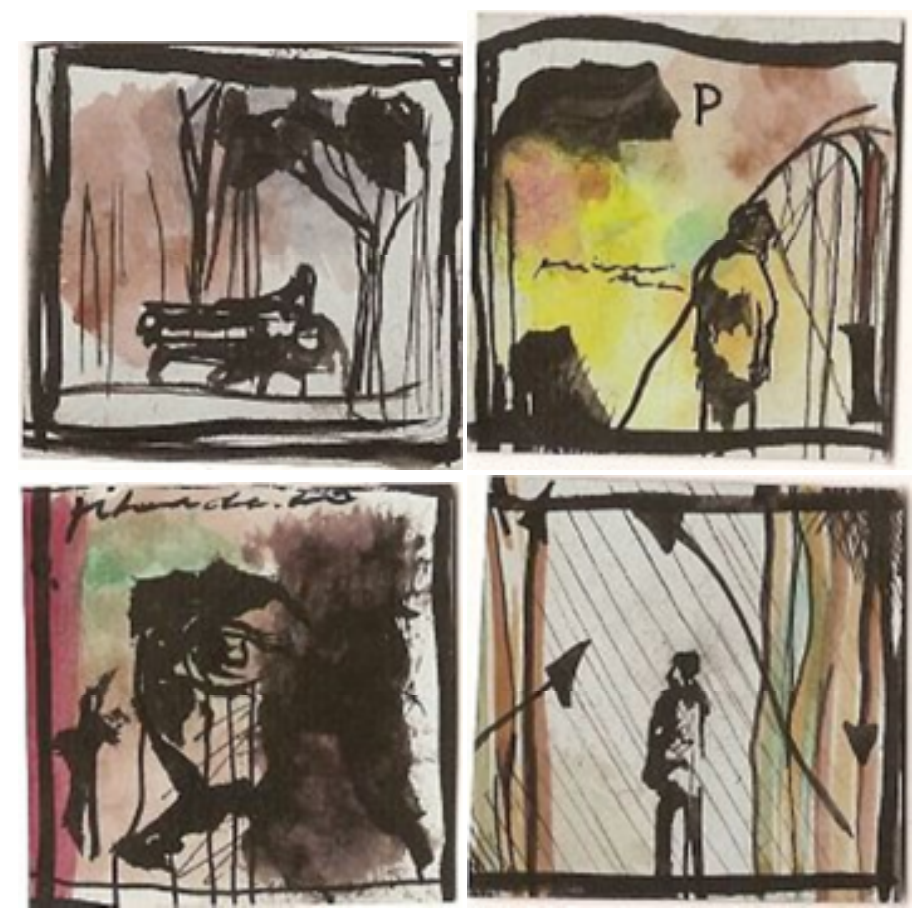

Ilustração Douglas Veloso

\title{
Ensino de leitura de textos literários: a posição do educador na esfera pública(1)
}

\section{Marcelo Chiaretto}

Marcelo Chiaretto é doutor em Literatura Comparada pela Faculdade de Letras da UFMG, professor na mesma Faculdade e no COLTEC/UFMG e membro do Programa A tela e o texto.

\section{Resumo}

Este artigo pretende analisar perspectivas de trabalho do professor de leitura de textos literários na esfera pública contemporânea. Conforme uma proposta de gestão democrática, a sala de aula funcionaria assim como um prolongamento da esfera pública tradicional, uma vez que os alunos, tendo como ponto disjuntor a leitura de um texto literário, teriam chance de explorar suas idéias em uma situação de prática social discursiva, como um debate aberto às diferenças sociais e políticas. 
Palavras-chave: ensino de leitura de textos literários, políticas públicas de educação.

Trabalhar com um suposto poder imaterial como a literatura é, para muitos profissionais, semear, plantar, colher e abandonar uma terra sem dono. Segundo Umberto Eco, estamos rodeados de poderes imateriais, que não se restringem aos chamados valores espirituais, como o das doutrinas religiosas. E entre esses poderes pode-se incluir também o da tradição literária, isto é, do complexo de textos que a humanidade produziu e produz, não com fins práticos, mas gratia sui, por amor a si mesma, e que são lidos por prazer, elevação espiritual ou para ampliar os conhecimentos(1).

Se for verdade que os objetos literários são imateriais em parte, pois geralmente se encarnam em veículos de papel, houve um tempo em que eles se encarnavam na voz de quem recordava a tradição oral de toda uma comunidade. Essa é uma finalidade absolutamente oportuna para o texto literário. No processo de se pensar as razões da falta de leitura, convém perceber que, no caso específico do texto literário, há uma despolitização acentuada dos estudiosos em vista da urgente necessidade de mais e mais ponderações. Hoje, se se pensar no terreno político, vê-se que o ensino de literatura já assumiu um fim prático e é provável, portanto, que se trata hoje muito mais do controle da "funcionalidade" da literatura que de acabar com seu ensino, como defendem abertamente as propostas educacionais inscritas nos novos Parâmetros Curriculares Nacionais.

Trata-se - e isto é fundamental - de não esquecer que o objetivo possível na contemporaneidade é aprimorar os controles, buscando não paralisar o que Umberto Eco chamou de "ampliação dos conhecimentos". O professor de literatura por seu lado, hoje decididamente um professor de leitura de textos literários, não pode prescindir do debate público, dos benefícios de uma democracia de opinião pública instalada em sala de aula, na qual os alunos não teriam alternativa senão prestar atenção nas opiniões, nos elementos participativos. Nessa perspectiva, o "controle da funcionalidade" ficaria nas mãos dos interessados de fato. Vistos como direitos públicos, a leitura de um texto literário e o conseqüente debate de idéias encontrariam mais, e talvez melhores defensores, que o professor mergulhado em sua solidão, a se expressar sem ânimo para as paredes.

Convém mencionar que o maior objetivo deste artigo não é somente enfatizar a necessidade da leitura de textos literários, mas sobretudo defender a imagem do professor de 
literatura ou, para que fique bem claro, do professor de leitura de textos literários como sendo um educador social, um agente cultural e um produtor de identidades de forma concomitante. De fato, existe um poder exercido em nome do conjunto das comunidades, que transforma o professor em um ser político e as comunidades em algo como efetivas associações de interesses ligados a um modo de vida ideal. Com um parentesco tão próximo da retórica, na literatura se experimentam formas de crer e constroem-se verdades, é como um laboratório aberto, público - apesar de ainda elitista, consumido a princípio por um restrito grupo social letrado. Por isso, é urgente a modificação do esquema atual para algo que seja realmente representativo e participativo, isto é, algo possível para todos.

\section{A gestão democrática}

- problema para o professor de leitura de textos literários que faria de sua classe uma ágora no formato grego, isto é, uma arena política, são os interesses gerais - aqueles que correspondem ou contemplam a todos - chocando-se com os interesses particulares. A solução seria uma ação incessantemente comunicativa, fundada numa ânsia contumaz pelo convencimento durante todo o tempo. Quando o "mestre" evita as decisões, quando é negociador e aparador de todo e qualquer conflito ou embate para defender sua imagem de "mestre", o que permanece é apenas o lado calamitoso da democracia. O importante é que os conflitos entre os alunos sejam firmados apenas no plano das aparências, não havendo assim fatos, porém interpretações e especulações abertas a todas as racionalidades. A política democrática que esse professor poderia professar em sala de aula estaria então acompanhada de uma cultura cívica democrática. É o momento de atuação do professor enquanto agente cultural.

Em sala de aula, o professor de leitura de textos literários (conforme uma prática que legitima o lugar do soberano, do líder, do governante), pode exercer um poder normatizador sobre o campo da política e da ação social, quando, por exemplo, estabelece a "segurança da leitura do professor" como técnica normal de "leitor soberano". Desse modo, firma-se a possibilidade de uma leitura literária livre de risco e previsível para o aluno, instaurando assim uma gestão calculista do "literário" com uma finalidade administrativa e governamental.

Vale destacar que tal gestão calculista é agradável para um grupo hegemônico de alunos, ou seja, aqueles que consideram a leitura administrada pelo professor como a mais autorizada, a menos discutível e a mais cômoda. Nega-se a política enquanto "livre uso do mundo pelo homem" (2) (a política é vista como 
direito parcial, e não neutrol e se acredita na noção de "suspensão legal da lei" - atentando-se, no caso, às conquistas advindas da nova Lei de Diretrizes e Bases para a Educação Nacional - no ensino de leitura de textos literários. Assim, os alunos-sujeitos podem ser dispostos em zonas de anomia, com seus direitos (do homem e do cidadão) dissociados, de acordo com a necessidade de um consenso intersubjetivo orquestrado para contemplar todas as expectativas. Desse modo, - professor, sem o saber, passa a trabalhar com uma máquina político-jurídica de produção da exclusão social de uma comunidade de leitores em potencial.

Considerando-se a capacidade de fortalecer ou ofuscar sujeitos políticos - ou representações políticas - em uma situação de legalidade discutível, o ensino de leitura de textos literários em uma instituição escolar logra colocar em sentido precário conceitos que devem estar claros para os alunos de uma sociedade da ampla e irrestrita informação: o que é ou não é legal? O que é ou não é justo? Como se realiza a suspensão legal da lei? Como é possível desativar essa suspensão, combatendo a violência do professor incomunicável e despolitizado, da escola como um monumento ao atraso e do aluno sem livre-arbítrio, sem interesse pela ação social, sem educação para uma vida em comunidade? Como estabelecer esse combate no campo jurídico, conforme uma noção de democracia, de liberdades individuais, de direitos adquiridos e responsabilidades? Como trabalhar sabendo da atuação daquilo que Deleuze chamou de "agentes de fabricação de consensos" (3), como a mídia e a publicidade, que comandam eficazmente a sociedade da informação, segundo o filósofo, uma "sociedade de controle", que dominaria uma contemporaneidade pósdisciplinar?

Atualmente, com os crescentes estudos sobre educação em uma perspectiva até mesmo transdisciplinar, os professores têm melhores condições de ajudar e de, propriamente, prejudicar. Uma sala de aula, como o Estado-nação, finge estabelecer uma forma de solidariedade intersubjetiva, uma universalidade recriada, em nome da manutenção de imaginários ideais coletivos. A melhor contraposição a tal quadro é um espaço regulador, que assume suas propriedades coletivistas em vista da manutenção de instituições capazes de fomentar novas e enriquecedoras experiências. No trabalho com os alunos, a firmeza no exercício e na deliberação dos poderes manterá o jogo de forças no qual nenhum "contendor" disporá de meios de manter para sempre a hegemonia de sua leitura, por mais competente que seja o professor, o aluno ou o grupo que 0 secunda.

Maquiavel dá alguns subsídios interessantes para se entender a sala de aula de leitura de textos literários como uma espécie 
de comunidade. Na visão do florentino, há o "príncipe", os "grandes" e o "povo" (4). Para que os dirigentes conquistem e mantenham o controle do poder, os fins do Estado - que aqui se pode entender como a escola - devem ser a glória, a grandeza e o bem comum. A disposição do professor de buscar fazer o que for necessário para alcançar a grandeza ou a glória cívica, Maquiavel chamou virtù, termo que poderia ser traduzido por "competência" (5). Misto de lucidez, determinação, conhecimento e habilidade, a virtù é a principal qualidade que um príncipe ou um Estado deve possuir para tornar-se grande e assim se manter.

Transpondo essa proposta para a escola, ou melhor, para a aula de leitura, a melhor postura para o professor é evitar o triunfo de um ponto de vista, com o reconhecimento da magnitude da diversidade. Com a habilidade política de um legítimo estadista, o educador agirá com base na idéia de coerência a fim de incentivar e intermediar leituras e projetos. Sua autoridade será então assegurada sem aviltamento, porém, pela força do seu carisma, de sua determinação, de sua eficácia, evitando a arrogância suscitada pela erudição e pela figura do "leitor exemplar" a todo custo. Para o educador, seria fundamental diferenciar poder e potência no trabalho de conquista do corpo discente. Na confluência com Foucault, Deleuze informa que o poder sempre tem por objetivo separar as pessoas submetidas daquilo que elas podem realizar. A potência por sua vez é o prazer da conquista, não a conquista que leva à submissão das pessoas, mas aquela que tem "o mesmo sentido de quando se diz que um pintor conquistou uma cor" (6).

Jürgen Habermas publicou um livro há aproximadamente 40 anos que traz informações bem oportunas. No livro, chamado Mudança estrutural da esfera pública (7), o autor define a "esfera pública" como uma zona para "discurso" ou "debate" na qual idéias são exploradas, instituições e políticas, criticadas, e uma "visão pública" pode ser expressa. Seria uma espécie de primado da opinião pública, o que estaria bem de acordo com a proposta da metodologia alternativa de ensino de leitura de textos literários ora preconizada.

A sala de aula funcionaria assim como um prolongamento da esfera pública tradicional, uma vez que os alunos, tendo como ponto disjuntor a leitura de um texto literário, teriam chance de explorar suas idéias em uma situação de prática social discursiva, como um debate público. Tal "esfera pública", é bom explicar, não poderia assumir um mesmo ponto de vista, uma mesma fonte de idéias, mas enfatizar a noção de uma arena de debate e crítica, fomentada por uma sociedade civil, soberana, cidadã, consciente da dignidade da pessoa humana, da livre 
iniciativa, do pluralismo de idéias e principalmente da premência do colaboracionismo.

Estando tal "esfera pública" secundada pelo ambiente escolar, um problema apareceria para o professor: o trato com os centros de avaliação e decisão. Os centros de avaliação podem ser dispostos no modo de rede, com alunos organizados em vários "centros" aptos a avaliarem a si próprios e aos outros. Os centros de decisão estariam estabelecidos da mesma forma, em formato de delegações, com o professor assumindo o papel do coordenador institucional e executivo.

No tocante à concepção da escola enquanto instituição organizacional, vale remeter aqui à noção de Derrida da literatura enquanto instituição democrática, pela possibilidade de abarcar inúmeros e diferenciados receptores, na defesa da liberdade e do direito. De fato, pode-se entender - ensino da leitura de textos literários dessa forma, ao se pensar que a expressão instituição estaria presente na sala de aula no momento em que os alunos compartilhassem, a partir da experiência da leitura, suas memórias sociais e o horizonte de suas ações futuras, como informa Merleau-Ponty (8). No entanto, em contraste com a visão de Derrida, a noção de instituição ora em exposição seria limitadora, ou seja, o leitor atuaria em campos cerceadores da polissemia, o que equivale a dizer que os sentidos teriam suas respectivas dimensões, não havendo assim qualquer espaço para um "vale-tudo" na leitura. Imaginando-se a classe como um prolongamento da sociedade civil, seu aspecto institucional estaria nas leituras coligadas umas às outras, conforme associações internas, em uma lógica complexa e precária, com cada leitura mantendo a existente quando a ultrapassasse, em um contínuo "ir mais longe" a interpretar e deformar. Seriam novos sentidos, porém já de certa forma antecipados. Tal situação teria, certamente, o professor como mediador, a estimular e expandir os sentidos já existentes.

\section{Uma comunidade solidária e conflituosa}

Em uma sala de aula de uma escola pública ou mesmo particular, há interesses que se projetam, há conflitos muitas vezes velados entre grupos representativos em busca de uma política social de inclusão. Em um curto momento em que se fala de literatura isoladamente, os novos Parâmetros Curriculares Nacionais chegam a focar tal tema ao afirmar:

Na escola, a exigência de se dar espaço para a verbalização do nãodito será uma possibilidade para a construção de múltiplas identidades. É um grande passo para a sistematização da identidade de grupos que sofrem processos de deslegitimação social. Aprender a conviver com as diferenças, reconhecê-las como legítimas e saber defendê-las em espaço público fará com que o aluno reconstrua a 
auto-estima. A literatura é um bom exemplo do simbólico verbalizado. Guimarães Rosa procurou no interior de Minas Gerais a matéria-prima de sua obra: cenários, modos de pensar, sentir, agir, de ver o mundo, de falar sobre o mundo, uma bagagem brasileira que resgata a brasilidade. Indo às raízes, devastando imagens préconceituosas, legitimou acordos e condutas sociais, por meio da criação estética.

Estaria aí uma das grandes funções do professor ao trabalhar a leitura de textos literários: dar espaço para a verbalização das variadas representações sociais e culturais. Dessa forma, pode-se dizer que o professor, sabendo compreender o jogo político presente no ato de se ensinar leitura de textos literários, terá a perspectiva de exercer uma liderança propriamente política, no momento em que servir de mediador para demandas sociais e interesses diferentes. Ele não apenas se esforçaria por proporcionar a convivência entre culturas, mas também intentaria firmar um lugar de debates com objetivos específicos - considerando-se as liberdades e os encargos do leitor em uma leitura literária. É o momento de atuação do professor como produtor de identidades.

No caso da leitura de textos literários em uma sala de aula marcada pela heterogeneidade, a tônica comportamental do professor deverá ser o respeito às diferenças individuais em vista da manutenção estratégica dos embates que darão esteio ao coletivo. Conforme aponta Edgar Morin:

- problema crucial do nosso tempo é o da necessidade de um pensamento apto a enfrentar o desafio da complexidade do real, isto é, de perceber as ligações, interações e implicações mútuas, os fenômenos multidimensionais, as realidades que são, simultaneamente, solidárias e conflituosas (como a própria democracia que é o sistema que se nutre de antagonismos regulandoos). (10)

o produto principal desta nova metodologia, ou deste modelo democrático participativo de ensino, seria a concepção da prática escolar enquanto prática social, ou seja, dependente de um contato intersubjetivo ao mesmo tempo solidário e conflituoso entre os membros da comunidade de leitores. É relevante enfatizar que o ideal não seria apenas a produção de um leitor bom consumidor da palavra escrita, capaz de compreender palavras e parafrasear textos, de forma rápida, fluente e eficaz (11). De fato, conceber a leitura apenas como um processo de consumir e armazenar informação é somente uma maneira de continuar a reproduzir as situações de vantagem e desvantagem nas instituídas relações de poder, em nada contribuindo, como muitas vezes se faz crer, para a verdadeira formação de leitores.

A meta implica que as pessoas aprendam a usar a linguagem e a escrita para questionar o que parece normal e natural e assim 
redesenhar e criar mundos sociais alternativos. Mais que isso, a meta maior implica se comunicar com a comunidade e entender suas demandas, suas expectativas, e então avaliá-las, fazendo com que os possíveis espaços alternativos sejam de fato estimulantes da ação política e acolhedores sobretudo da cultura iletrada. Surge assim o horizonte para a inclusão, para novos valores e compreensões diante da inaceitável realidade do abandono do livro, da leitura, da escola e da esfera pública.

\section{Abstract}

This article aims at investigating the role of the literature teacher in contemporary context. In a democratic sense, the classroom should resemble the traditional public sphere, where pupils would deal with literary texts as a chance to exploit their ideas practicing discourse, and where the debate would be opened to the social and political differences.

Key-words: education of reading of literary texts, public politics of education.

\section{Notas}

(1) Cf. ECO, 2006

(2) Cf. AgAMBEN, 2004.

(3) Cf. DELEUZE \& PARNET, 2004.

(4) Cf. MAQUIAVEL, 1996.

(5) Cf. MAQUIAVEL, 2000.

(6) Cf. DELEUZE \& PARNET, 2004.

(7) Cf. HABERMAS, 2003.

(8) Há um livro de Maurice Merleau-Ponty, L'Institution - La Passivité (Ed. Belin, 2003), bem oportuno e interessante para se entender a expressão Instituição.

(8) MEC, 2000, p.142.

(9) MORIN, 2005, p.74.

(9) Cf. DIONíSIO, 2000.

(10) MORIN, 2005, p.74.

(11) Cf. DIONísio, 2000. 


\section{Bibliografia}

AgAmBEN, G. Homo Sacer. O poder soberano e a vida nua. Belo Horizonte, Editora UFMG, 2002 .

ECO, Umberto. A definição da arte. $1^{a}$.ed. Lisboa: Edições 70, 2006.

DELEUZE, G \& PARNET, C. Diálogos. Lisboa: Relógio D’água, 2004 .

Dionísio, Maria de Lourdes. A construção escolar de comunidades de leitores: leituras do Manual de Português. Coimbra: Almedina, 2000.

HABERMAS, J. Mudança estrutural da esfera pública. Rio de Janeiro: Tempo Brasileiro, 2003 .

MAQUiAVEL, Nicolau. Comentários sobre a primeira década de Tito Lívio. Brasilia: UNB, 2000 .

- O príncipe. Rio de Janeiro: Paz e Terra, 1996.

MERLEAU-PONTY, M. L'Institution - La Passivité. Paris: Belin, 2003.

PARÂMETROS CURRICULARES NACIONAIS. MEC, 2000.

MORIN, Edgar. Educação e complexidade: os sete saberes e outros ensaios. São Paulo: Cortez, 2005. 